\title{
Response of maize genotypes to the infection by selected Fusarium isolates from Liseola section
}

\section{Reakcja genotypów kukurydzy na infekcję wybranymi izolatami grzybów z rodzaju Fusarium sekcji Liseola}

\author{
Elżbieta Czembor ${ }^{1}$, Seweryn Frasiński ${ }^{1}$, Łukasz Stępień ${ }^{2 *}$
}

Summary

Ear rot is an insidious disease of maize caused by Fusarium spp. and can reduce yield and quality of harvested grain, mainly because of its contamination with mycotoxins produced by some fungi. Depending on weather conditions, ear rot can be caused by F. graminearum and fungi belonging to Liseola section: F. verticillioides, F. proliferatum, F. subglutinans and F. temperatum. Recently, the frequency of occurrence of $F$. temperatum increased in the populations of Fusarium spp. existing in Poland. Based on the results obtained from the carried out studies, it can be concluded that $F$. temperatum could be more aggressive than other species from Liseola section.

Key words: Fusarium temperatum; Liseola section; ear rot; maize

\section{Streszczenie}

Fuzarioza kolb kukurydzy powodowana przez grzyby z rodzaju Fusarium spp. wpływa ujemnie na wielkość plonu, jak i na jego jakość, a metabolity wtórne wytwarzane przez te grzyby powodują groźne choroby ludzi i zwierząt. Obecnie, w zależności od przebiegu warunków atmosferycznych, sprawcami fuzariozy kolb są: Fusarium graminearum oraz grzyby z sekcji Liseola: F. verticillioides, F. proliferatum, F. subglutinans i jego gatunek siostrzany - F. temperatum. Gatunek F. temperatum występuje na terenie Polski z coraz większą częstością. Jak wykazano w bieżących badaniach, może być bardziej agresywny niż inne gatunki należące do sekcji Liseola.

Słowa kluczowe: Fusarium temperatum; sekcja Liseola; fuzarioza kolb; kukurydza

\footnotetext{
${ }^{1}$ Instytut Hodowli i Aklimatyzacji Roślin - Państwowy Instytut Badawczy

Radzików, 05-870 Błonie

${ }^{2}$ Instytut Genetyki Roślin Polskiej Akademii Nauk

Strzeszyńska 34, 60-479 Poznań

*corresponding author: Iste@igr.poznan.pl
} 


\section{Wstęp / Introduction}

Kukurydza należy do roślin o dużym znaczeniu gospodarczym, zarówno w Polsce, jak i na całym świecie. Jest to roślina dająca wysoki plon zarówno przy uprawie na ziarno, jak i na kiszonkę. Wykorzystuje się ją również w przemyśle spożywczym, chemicznym, papierniczym, fermentacyjnym i farmaceutycznym. Stanowi surowiec do produkcji biopaliw w związku z Protokołem zawartym w Kioto mającym na celu ograniczenie emisji gazów cieplarnianych.

Choroby w istotny sposób wpływają na wielkość i jakość plonu ziarna oraz zielonej masy kukurydzy. Do najważniejszych z nich należy fuzarioza kolb powodowana przez grzyby z rodzaju Fusarium spp. W zależności od rejonu i warunków atmosferycznych, głównymi sprawcami tej choroby są: Fusarium graminearum Schwabe, który produkuje deoksyniwalenol i zearalenon oraz F. verticillioides (Sacc.) Nirenberg, który produkuje fumonizyny. Duże znaczenie ma również F. proliferatum (Matsush.) Nirenberg, który produkuje fumonizyny (Leslie 1995; Velluti i wsp. 2000; Logrieco i wsp. 2002; Dorn i wsp. 2011; Boutigny i wsp. 2012). Mniej istotnym gatunkiem jest $F$. subglutinans (Wollenw. and Reinking) Nelson, Toussoun \& Marasas i F. sporotrichioides Scherb. (Chełkowski i wsp. 1987; Leslie 1995; Vigier i wsp. 1997). Na podstawie badań prowadzonych na terenie Polski stwierdzono, że dominujące gatunki to $F$. verticillioides oraz F. graminearum (badania składu gatunkowego grzybów z rodzaju Fusarium spp. oraz ocenę zagrożenia skażeniem ziarna kukurydzy mykotoksynami fuzaryjnymi prowadzono w latach 2008-2013 uwzględniając 14 lokalizacji położonych w 4 rejonach Polski: południowo-zachodnim, południowo-wschodnim, centralnym i zachodnim). Badania te wykazały również, że w populacji Fusarium spp. zasiedlającej ziarno kukurydzy na terenie Polski występuje nowy gatunek $-F$. temperatum, zidentyfikowany po raz pierwszy w Belgii w 2011 roku przez Scauflaire i wsp. (2011, 2012). Potwierdzono, że spośród gatunków z rodzaju Fusarium, potencjalnymi sprawcami fuzariozy kolb kukurydzy na terenie Polski są: F. verticillioides, F. proliferatum, F. graminearum i F. temperatum (Czembor i wsp. 2014, 2015), dlatego zasadną wydaje się dalsza charakterystyka patogeniczności tych gatunków w stosunku do różnych genotypów kukurydzy.

Mykotoksyny produkowane przez grzyby z rodzaju Fusarium dyskwalifikują ziarno do dalszego przetwórstwa, ponieważ stanowią zagrożenie dla zdrowia ludzi i zwierząt. Związki te gromadzone są w różnych tkankach powodując m.in. wymioty, uszkodzenia szpiku kostnego, anemię, zmiany narządów wewnętrznych, zmniejszenie łaknienia, spadek masy ciała i zaburzenia ciąży (Ueno 1980; Chełkowski 1989; Rotter i wsp. 1996; Shephard i wsp. 1996; Logrieco i wsp. 2002; Logrieco i Visconti 2004). Badania prowadzone na terenie Polski przez Państwową
Inspekcję Sanitarną w latach 2004-2006 potwierdzily, że skażenie $\mathrm{w}$ wybranych produktach spożywczych przekroczyło dopuszczalne normy (Rybińska i wsp. 2008). Potwierdzily to również badania Czembor i wsp. (2012).

Za najbardziej opłacalną i przyjazną środowisku metodę ochrony roślin przed czynnikami chorobotwórczymi uważa się wykorzystanie $\mathrm{w}$ uprawie odmian odpornych (Meissle i wsp. 2010; Zijlstra i wsp. 2011). Dlatego coraz większą wagę przywiązuje się do selekcji materiałów wyjściowych wykorzystywanych w hodowli pod względem odporności na fuzariozę kolb (Reid i wsp. 2002; Munkvold 2003; Czembor i wsp. 2005, 2011a, b, 2013a, b; Mesterházy i wsp. 2012). O stopniu porażenia roślin decyduje przede wszystkim stopieńodporności rośliny, agresywność patogena oraz czynniki klimatyczne. Nadal dyskutowane jest zagadnienie, czy wysoka odporność na porażenie przez grzyby z rodzaju Fusarium spp. świadczy również o odporności genotypu na zdolność do gromadzenia mykotoksyn (Munkvold i wsp. 1997; Reid i wsp. 1999; Duncan i Howard 2010; Mesterházy i wsp. 2012).

Celem pracy było porównanie agresywności gatunków należących do sekcji Liseola, jako sprawców fuzariozy kolb kukurydzy: Fusarium temperatum oraz gatunku siostrzanego -F. subglutinans, F. verticillioides oraz F. proliferatum w warunkach polowych po zakażeniach sztucznych.

\section{Materiały i metody / Materials and methods}

Doświadczenia założono na polach doświadczalnych Instytutu Hodowli i Aklimatyzacji Roślin - Państwowego Instytutu Badawczego (IHAR - PIB) w Radzikowie. Nasiona wysiewano w siewie rzędowym, średnio 20 roślin $\mathrm{w}$ rzędzie. Rozstawa pomiędzy roślinami w rzędzie wynosiła średnio $17,5 \mathrm{~cm}$, a pomiędzy rzędami $75 \mathrm{~cm}$. Zastosowano nawożenie w ilości: $200 \mathrm{~kg} / \mathrm{ha} \mathrm{N}, 80 \mathrm{~kg} / \mathrm{ha} \mathrm{P}_{2} \mathrm{O}_{5}$ i $120 \mathrm{~kg} / \mathrm{ha} \mathrm{K}{ }_{2}$.

Agresywność gatunków należących do sekcji Liseola, jako potencjalnych sprawców fuzariozy kolb określano po zakażeniach sztucznych kolb roślin dwóch elitarnych linii wsobnych S50676 i S68911. Podstawą wyboru materiału roślinnego były badania wstępne, na podstawie których stwierdzono, że charakteryzuje się on zróżnicowaną odpornością na fuzariozę kolb przy infekcji naturalnej.

\section{Patogen}

Do przygotowania inokulum wykorzystano 8 jednozarodnikowych kultur grzybów z rodzaju Fusarium spp. sekcji Liseola: 3 izolaty F. temperatum (FT 180, FT 326 oraz FT 317), 2 izolaty F. subglutinans (FS 447, FS 431), 2 izolaty $F$. verticillioides (FV 463, FV 429) i jeden izolat F. proliferatum (FP 436). Izolaty należały do kolekcji Pracowni Traw Pastewnych i Roślin Motylkowatych IHAR 
- PIB w Radzikowie oraz Instytutu Genetyki Polskiej Akademii Nauk. Zostały one wyosobnione w trakcie badań mających na celu monitorowanie grzybów z rodzaju Fusarium spp. zasiedlających ziarno kukurydzy na terenie Polski. Odkażone powierzchniowo ziarniaki wykładano na pożywkę PDA. Szalki inkubowano w ciemności, a następnie pod światłem UV w celu stymulacji zarodnikowania. Kultury o charakterystycznej dla Fusarium spp. barwie i kształcie zarodników izolowano na szalki z pożywką PDA i SNA, tak aby móc dokonać identyfikacji metodą molekularną.

Do przygotowania inokulum, izolaty po odszczepieniu na szalki Petriego z pożywką PDA inkubowano przez okres 2 tygodni w temperaturze $20-22^{\circ} \mathrm{C}$. Następnie grzybnię zmywano i rozcieńczano sterylnym, wodnym podłożem agarowym (3 g agaru/l wody), kontrolując liczbę zarodników w powstałym roztworze. Inokulację wykonano zawiesiną o stężeniu $5 \times 10^{5}$ zarodników/ml.

\section{Test odpornościowy i ocena fenotypowa stopnia odporności na fuzariozę kolb}

Zakażenia sztuczne przeprowadzono po mechanicznym uszkodzeniu ziarniaków 10-12 dni od daty kwitnienia kwiatostanów męskich (faza początkowej dojrzałości mlecznej BBCH 73), poprzez iniekcję 1,5 ml zawiesiny zarodników na wysokości $1 / 3$ od podstawy kolby wykorzystując do tego celu strzykawkę czterokanałową - 7 roślin w każdym z 3 powtórzeń dla każdego izolatu. Ocenę objawów porażenia kolb badanych linii wsobnych przez $F$. temperatum i pozostałe gatunki z rodzaju Fusarium przeprowadzono w fazie dojrzałości pełnej opisując procent kolby z objawami choroby w stosunku do całej powierzchni.

\section{Analizy statystyczne}

Doświadczenia zakładano w układzie losowanych bloków. Do oceny istotności różnic dla ocen stopnia odporności na fuzariozę kolb zastosowano dwuczynnikową analizę wariancji. Po odrzuceniu hipotezy o braku różnic pomiędzy obiektami, dokonano szczegółowego porównania obiektów pod względem odporności na fuzariozę kolb, przy użyciu testu Fishera najmniejszej istotnej różnicy. Analizę danych przeprowadzono za pomocą programu InfoStat.

\section{Wyniki i dyskusja / Results and discussion}

Jedną z najgroźniejszych chorób kukurydzy jest fuzarioza kolb powodowana przez grzyby z rodzaju Fusarium spp. Najczęściej, w zależności od warunków pogodowych, są to $F$. graminearum produkujący deoksyniwalenol oraz zearalenon lub $F$. verticillioides produkujący fumonizyny (Shepard i wsp. 1996; Logrieco i wsp. 2002; Voss i wsp. 2006). Dyrektywy unijne (Rozporządzenie 2007) dyskwalifikują możliwość wykorzystania ziarna, w którym zawartość toksyn przekracza dopuszczalne normy. Nawet niewielki stopień porażenia kolb przez Fusarium spp. wpływa na poziom skażenia ziarna mykotoksynami.

Najnowsze badania epidemiologiczne prowadzone przez Czembor i wsp. (2012, 2014, 2015) wykazały, że w Polsce w populacji grzybów z rodzaju Fusarium zasiedlających ziarno kukurydzy, które są potencjalnymi sprawcami fuzariozy kolb, dominują: F. graminearum, F. verticillioides, $F$. proliferatum i $F$. subglutinans. Po raz pierwszy stwierdzono również występowanie nowego gatunku $-F$. temperatum, który jest gatunkiem siostrzanym $F$. subglutinans. W badaniach tych szczegółowo przeanalizowano wpływ warunków atmosferycznych występujących na terenie całej Polski na zróżnicowanie populacji, uwzględniając dane pogodowe historyczne dla lat 1958-2004, jak i bieżące (Czembor i wsp. 2015).

$\mathrm{W}$ trakcie przeprowadzonych badań warunki pogodowe również sprzyjały rozwojowi choroby, dzięki czemu uzyskane wyniki pozwoliły zróżnicować badane genotypy kukurydzy pod kątem reakcji na infekcję izolatami czterech gatunków Fusarium (sekcja Liseola) potencjalnie różniących się agresywnością: $F$. verticillioides (2 izolaty), F. proliferatum (1 izolat), F. subglutinans (2 izolaty) oraz $F$. temperatum (3 izolaty) (tab. 1, rys. 1). Zróżnicowanie stopnia porażenia roślin było istotne zarówno pomiędzy gatunkami, jak i w obrębie tego samego gatunku, stopień porażenia wahał się od $5 \%$ do prawie $30 \%$, jednakże w większym stopniu zależał

Tabela 1. Analiza wariancji dla stopnia agresywności izolatów Fusarium temperatum, F. subglutinans, F. verticillioides, F. proliferatum w stosunku do linii wsobnych kukurydzy po zakażeniach sztucznych kolb

Table 1. Fixed model analysis of variance for aggressiveness level of Fusarium temperatum, F. subglutinans, F. verticillioides and $F$. proliferatum isolates after inoculation of maize inbred lines

\begin{tabular}{l|c|c|c|c}
\hline \multicolumn{1}{c|}{ Zmienna - Variable } & $\begin{array}{c}\text { Liczba stopni swobody } \\
\text { Degrees of freedom }\end{array}$ & $\begin{array}{c}\text { Średni kwadrat odchyleń } \\
\text { Mean square }\end{array}$ & $\begin{array}{c}\text { Wartość F } \\
\text { F value }\end{array}$ & $\begin{array}{c}\text { Wartość P } \\
\text { P value }\end{array}$ \\
\hline Izolat - Isolate & 7 & 1624,33 & 34,98 & $<0,0001$ \\
\hline Linia - Genotype & 1 & 194,29 & 4,18 & 0,0416 \\
\hline Izolat $\times$ linia - Isolate $\times$ genotype & 7 & 345,58 & 7,44 & $<0,0001$ \\
\hline Błąd - Error & 319 & 46,44 & - & - \\
\hline
\end{tabular}




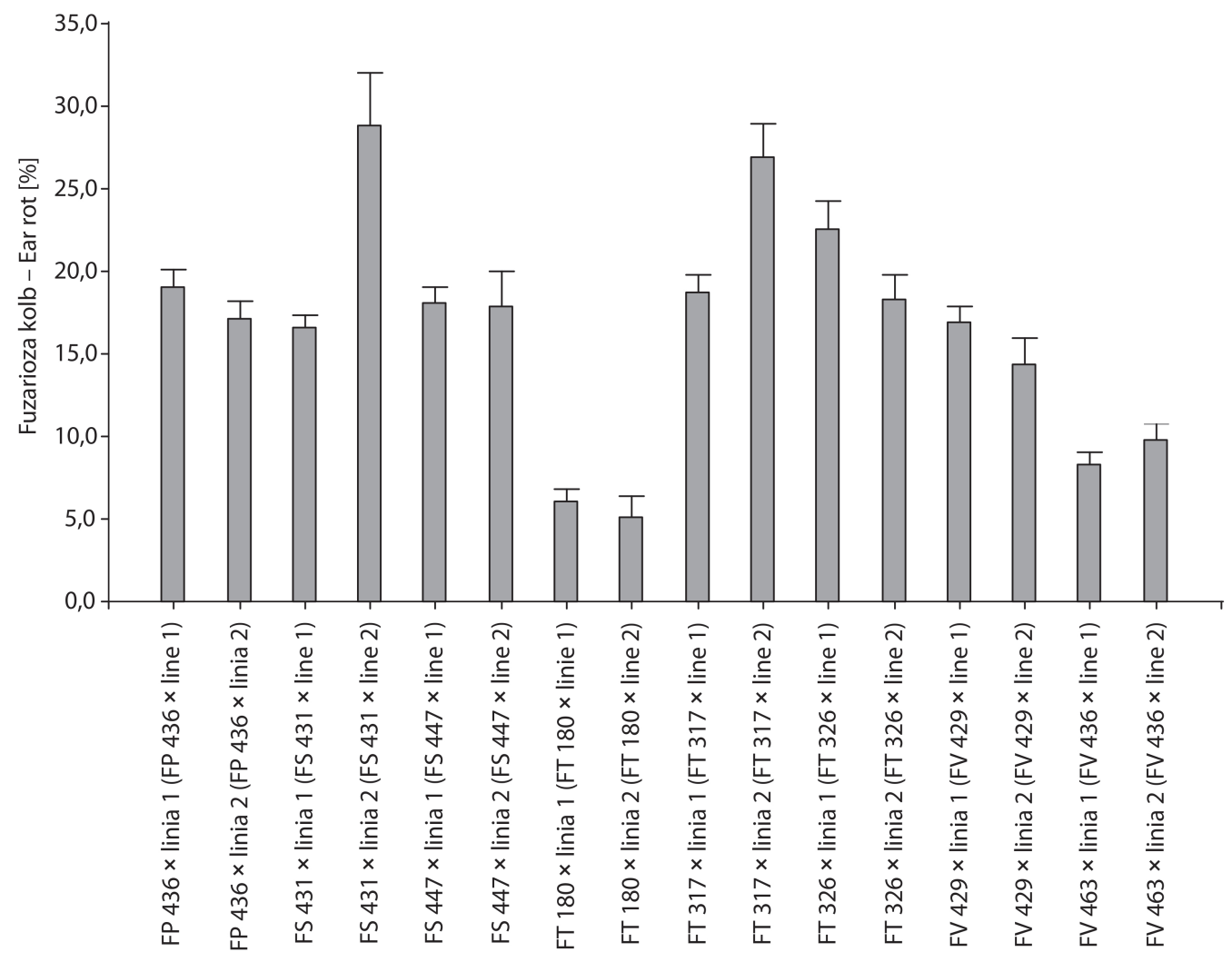

Rys. 1. Zróżnicowanie pomiędzy izolatami Fusarium temperatum, F. subglutinans, F. verticillioides, F. proliferatum pod względem agresywności na podstawie danych stopnia porażenia dwóch linii wsobnych po zakażeniach sztucznych

Fig. 1. Differences in disease scores of two maize inbred lines artificially inoculated with Fusarium temperatum, F. subglutinans, $F$. verticillioides and $F$. proliferatum strains

od izolatu niż genotypu rośliny (rys. 1). Na uwagę zasługiwały dwa izolaty F. temperatum, które charakteryzowały się wysoką patogenicznością zarówno w stosunku do pierwszej, jak i drugiej linii wsobnej (FT 317 oraz FT 326). Natomiast trzeci izolat $F$. temperatum okazał się najmniej patogeniczny spośród wszystkich badanych, podobnie jak jeden z izolatów F. verticillioides (FV 463). Drugi izolat $F$. verticillioides (FV 429) charakteryzował się zbliżoną agresywnością do izolatów F. proliferatum (FP 436) i F. subglutinans (FS 447). $\mathrm{Na}$ uwagę zasługiwał również fakt, że genotyp w sposób istotny wpływał na rozwój choroby, co potwierdza badania zespołów badawczych, zajmujących się poszukiwaniem źródeł odporności na fuzariozę kolb metodą rodowodową na podstawie ocen fenotypowych oraz po określeniu zawartości toksyn w próbach ziarna (Reid i wsp. 1993, 1996,
2002; Czembor i wsp. 2005, 2011a, b, 2013a, b; Presello i wsp. 2005, 2011; Mesterházy i wsp. 2012).

\section{Wnioski / Conclusions}

1. Izolaty F. temperatum, gatunku coraz częściej stwierdzanego w różnych krajach Europy, mogą być równie patogeniczne w stosunku do kukurydzy, jak inne gatunki z sekcji Liseola, takie jak F. verticillioides, F. subglutinans czy F. proliferatum.

2. Stwierdzono zróżnicowanie pomiędzy izolatami F. temperatum, sprawcy fuzariozy kolb kukurydzy, dla stopnia agresywności w warunkach polowych.

\section{Literatura / References}

Boutigny A.-L., Beukes I., Small I., Zühlke S., Spiteller M., Van Rensburg B.J., Flett B., Viljoen A. 2012. Quantitative detection of Fusarium pathogens and their mycotoxins in South African maize. Plant Pathology 61 (3): 522-531. DOI: 10.1111/j.1365-3059 .2011.02544.x.

Chełkowski J. 1989. Mycotoxins associated with corn cob fusariosis. p. 53-62. In: "Fusarium - Mycotoxins, Taxonomy and Pathogenicity" (J. Chełkowski, ed.). Elsevier, Amsterdam, 492 pp. 
Chełkowski J., Kwaśna H., Zajkowski P., Visconti A., Bottalico A. 1987. Fusarium sporotrichoides Scherb. and trichothecenes associated with Fusarium-ear rot of corn before harvest. Mycotoxin Research 3 (2): 111-113. DOI: 10.1007/BF03191997.

Czembor E., Matusiak M., Ochodzki P. 2013a. Odporność mieszańców kukurydzy na fuzariozę kolb powodowaną przez Fusarium graminearum i F. verticillioides w Polsce w latach 2008-2009. [Resistance of maize hybrids to ear rot caused by Fusarium graminearum and F. verticillioides in Poland in years 2008-2009]. Biuletyn Instytutu Hodowli i Aklimatyzacji Roślin 270: 55-73.

Czembor E., Matusiak M., Warzecha R. 2013b. Poszukiwanie źródeł odporności kukurydzy na fuzariozę kolb i zgorzel podstawy łodygi metodą rodowodową. [Looking for sources of resistance to ear rot and stalk rot on the basis of the pedigree selection]. Biuletyn Instytutu Hodowli i Aklimatyzacji Roślin 269: 123-139.

Czembor E., Ochodzki P., Sowa S., Grelewska K., Adamczyk J., Wojcik K. 2012. Fusarium complex, mycotoxins and biomass content in grain samples collected in Poland across 2008-2011. Proccedings Mycored North America, Ottawa, Kanada, 24-28.06.2012.

Czembor E., Stępień Ł., Waśkiewicz A. 2015. Effect of environmental factors on Fusarium species and associated mycotoxins in maize grain grown in Poland. PLoS ONE 10 (7): e0133644. DOI: 10.1371/journal.pone.0133644.

Czembor E., Warzecha R., Adamczyk J., Kurczych Z. 2005. Wytwarzanie materiałów wyjściowych kukurydzy o podwyższonej odporności na fuzariozę kolb i zgorzel podstawy łodygi. [Pre-breeding of maize with improved resistance to ear rot and stalk rot]. Biuletyn Instytutu Hodowli i Aklimatyzacji Roślin 236: 203-213.

Dorn B., Forrer H.R., Jenny E., Wettstein F.E., Bucheli T.D., Vogelgsang S. 2011. Fusarium species complex and mycotoxins in grain maize from maize hybrids trials and from grower's fields. Journal of Applied Microbiology 111 (3): 693-706. DOI: 10.1111/j.13652672.2011.05091.x.

Duncan K.E., Howard R.J. 2010. Biology of maize kernel infection by Fusarium verticillioides. Molecular Plant-Microbe Interactions 23 (1): 6-16. DOI: 10.1094/MPMI-23-1-0006.

Leslie J.F. 1995. Gibberella fujikuroi: available populations and variable traits. Canadian Journal of Botany 73 (S1): $282-291$. DOI: $10.1139 / \mathrm{b} 95-258$.

Logrieco A., Mulè G., Moretti A., Bottalico A. 2002. Toxigenic Fusarium species and mycotoxins associated with maize ear rot in Europe. p. 597-609. In: "Mycotoxins in Plant Disease" (A. Logrieco, J.A. Bailey, L. Corazza, B.M. Cooke, eds.). Springer, Dordrecht. ISBN 978-94-010-3939-0. DOI: 10.1007/978-94-010-0001-7_1.

Logrieco A., Visconti A. 2004. An Overview on Toxigenic Fungi and Mycotoxins in Europe. Kluwer Academic Publishers, Dordrecht, Boston, London, 252 pp. ISBN 1-4020-2645-5.

Meissle M., Mouron P., Musa T., Bigler F., Pons X., Vasileiadis V.P., Otto S., Antichi D., Kiss J., Pálinkás Z., Dorner Z., Van der Weide R., Groten J., Czembor E., Adamczyk J., Thibord J.-B., Melander B., Cordsen Nielsen G., Poulsen R.T., Zimmermann O., Verschwele A., Oldenburg E. 2010. Pests, pesticide use and alternative options in European maize production: current status and future prospects. Journal of Applied Entomology 134 (5): 357-375. DOI: 10.1111/j.1439-0418.2009.01491.x.

Mesterházy Á., Lemmens M., Reid L.M. 2012. Breeding for resistance to ear rot caused by Fusarium spp. in maize - a review. Plant Breeding 131 (1): 1-19. DOI: 10.1111/j.1439-0523.2011.01936.x.

Munkvold G.P. 2003 Epidemiology of Fusarium diseases and their mycotoxins in maize ears. European Journal of Plant Pathology 109 (7): 705-713. DOI: 10.1023/A:1026078324268.

Munkvold G.P., McGee D.C., Carlton W.M. 1997. Importance of different pathways for maize kernel infection by Fusarium moniliforme. Phytopathology 87 (2): 209-217. DOI: 10.1094/PHYTO.1997.87.2.209.

Presello D.A., Pereyra A.O., Iglesias J., Fauguel C.M., Sampietro D.A., Eyherabide G.H. 2011. Responses to selection of $\mathrm{S}_{5}$ inbreds for broad-based resistance to ear rots and grain mycotoxin contamination caused by Fusarium spp. in maize. Euphytica 178 (1): $23-29$. DOI: $10.1007 / \mathrm{s} 10681-010-0255-3$.

Presello D.A., Reid L.M., Butler G., Mather D.E. 2005. Pedigree selection for Gibberella ear rot resistance in maize. Euphytica 143 (1-2): 1-8. DOI: $10.1007 / \mathrm{s} 10681-005-6149-0$.

Reid L.M., Hamilton R.I., Mather D.E. 1996. Screening maize for resistance to Gibberella ear rot. Technical Bulletin 1996-5E. Eastern Cereal and Oilseed Research Centre. Research Branch, Agriculture and Agri-Food Canada, Ottawa, Canada, 40 pp.

Reid L.M., Nicol R.W., Ouellet T., Savard M., Miller J.D., Young J.C., Steward D.W., Schaafsma A.W. 1999. Interaction of Fusarium graminearum and $F$. moniliforme in maize ears: disease progress, fungal biomass, and mycotoxin accumulation. Phytopathology 89 (11): 1028-1037. DOI: 10.1094/PHYTO.1999.89.11.1028.

Reid L.M., Spaner D., Mather D.E., Bolton A.T., Hamilton R.I. 1993. Resistance of maize hybrids and inbred following silk inoculation with three isolates of Fusarium graminearum. Plant Disease 77: 1248-1251. DOI: 10.1094/PD-77-1248.

Reid L.M., Woldemariam T., Zhu X., Stewart D.W., Schaafsma A.W. 2002. Effect of inoculation time and point of entry on disease severity in Fusarium graminearum, Fusarium verticillioides, or Fusarium subglutinans inoculated maize ears. Canadian Journal of Plant Pathology 24 (2): 162-167. DOI: 10.1080/07060660309506991.

Rotter B.A., Prelusky D.B., Pestka J.J. 1996. Toxicology of deoxynivalenol (vomitoxin). Journal of Toxicology and Environmental Health 48 (1): 1-34. DOI: 10.1080/009841096161447.

Rozporządzenie komisji (WE) nr 1126/2007 z dnia 28 września 2007 r. zmieniające rozporządzenie (WE) nr 1881/2006 ustalające najwyższe dopuszczalne poziomy niektórych zanieczyszczeń w środkach spożywczych w odniesieniu do toksyn Fusarium w kukurydzy i produktach z kukurydzy. Dz. Urz. UE L 255/14 z dnia 29.09.2007 r.

Rybińska K., Postupolski J., Ledzion E., Kurpińska-Jaworska J., Szczęsna M. 2008. Programy monitoringowe realizowane przez Państwowa Inspekcję Sanitarną w zakresie zanieczyszczenia środków spożywczych mikotoksynami. [Monitoring programs realized by the State Sanitary Inspection concerning the contamination of selected foodstuffs bt mycotoxins]. Roczniki Państwowego Zakładu Higieny 59 (1): 1-7.

Scauflaire J., Godet M., Gourge M., Liénard C., Munaut F. 2012. A multiplex real-time PCR method using hybridization probes for the detection and the quantification of Fusarium proliferatum, F. subglutinans, F. temperatum and F. verticillioides. Fungal Biology 116 (10): 1073-1080. DOI: 10.1016/j.funbio.2012.07.011. 
Scauflaire J., Gourgue M., Munaut F. 2011. Fusarium temperatum sp. nov. from maize, an emergent species closely related to Fusarium subglutinans. Mycologia 103 (3): 586-597. DOI: 10.3852/10-135.

Shephard G.S., Thiel P.G., Stockenström S., Sydenham E.W. 1996. Worldwide survey of fumonisin contamination of corn and corn-based products. Journal of AOAC International 79 (3): 671-687. (PMID:8634537).

Ueno Y. 1980. Toxicological evaluation of trichothecene mycotoxins. p. 663-671. In: "Natural Toxins" 1st edition (D. Eaker, T. Wadström, eds.). Pergamon Press, Oxford, New York, 732 pp.

Velluti A., Marin S., Bettucci L., Ramos A.J., Sanchis V. 2000. The effect of fungal competition on colonization of maize grain by Fusarium moniliforme, F. proliferatum and $F$. graminearum and on fumonisin $\mathrm{B}_{1}$ and zearalenone formation. International Journal of Food Microbiology 59 (1-2): 59-66. DOI: 10.1016/S0168-1605(00)00289-0.

Vigier B., Reid L.M., Seifert K.A., Stewart D.W., Hamilton R.I. 1997. Distribution and prediction of Fusarium species associated with maize ear rot in Ontario. Canadian Journal of Plant Pathology 19 (1): 60-65. DOI: 10.1080/07060669709500574.

Voss K.A., Gelineau-van Waes J.B., Riley R.T. 2006. Fumonisions: current research trends in developmental toxicology. Mycotoxin Research 22 (1): 61-69. DOI: 10.1007/BF02954559.

Zijlstra C., Lund I., Justesen A.F., Nicolaisen M., Jensen P.K., Bianciotto V., Posta K., Balestrini R., Przetakiewicz A., Czembor E., van de Zande J. 2011. Combining novel monitoring tools and precision application technologies for integrated high-tech crop protection in the future (a discussion document). Pest Management Science 67 (6): 616-625. DOI: 10.1002/ps.2134. 